\title{
Targeted Deletion of MMP-9 Attenuates Myocardial Contractile Dysfunction in Heart Failure
}

\author{
K. S. MOSHAL, W. E. RODRIGUEZ, U. SEN, S. C. TYAGI \\ Department of Physiology and Biophysics, University of Louisville, School of Medicine, \\ Louisville, Kentucky, USA
}

Received February 19, 2007

Accepted May 4, 2007

On-line May 30, 2007

\begin{abstract}
Summary
Chronic volume overload (VO) on the left ventricle (LV) augments redox stress and activates matrix metalloproteinase (MMP) which causes the endocardial endothelial-myocyte (EM) disconnection leading to myocardial contractile dysfunction. VO-induced MMP-9 activation impairs cardiac functions, in part by endothelial endocardial apoptosis, but the role of MMP-9 on EM functions remains obscure. We conjecture that chronic VO activates MMP-9 and causes EM uncoupling. Arteriovenous fistula (AVF) was created in genetically identical wild type (WT) mice (FVB/NJ) and MMP-9 knockout mice (MMP-9KO, FVB.Cg$\left.\mathrm{MMPg}^{\mathrm{tm} 1 \mathrm{Tvu}} / J\right)$. Sham-operated mice were used as controls. Before experimentation the phenotype analysis of MMP-9KO mice was carried out. In-gel-gelatin zymography for MMP-9 activation was performed on LV homogenates. The EM functions were determined on LV rings using tissue myobath. We report a decrease in MMP-9 activity in left ventricular myocardial extracts in MMP-9 deficient mice after AVF. The responses to drugs affecting cardiac functions (acetylcholine (Ach), nitroprusside and bradykinin) were attenuated in AVF mice suggesting the impairment of EM coupling. Interestingly, the EM functions were restored in the MMP-9 deficient mice after AVF. We suggest a direct cause-and-effect relationship between MMP-9 activation and EM uncoupling in LV myocardium after chronic VO and the possible involvement of MMP-9 in myocardial contractile performance.
\end{abstract}

\section{Key words}

Endothelial-myocyte uncoupling • Ventricular contraction • Volume overload $\bullet$ LV Rings $\bullet$ Aortocaval shunt

\section{Corresponding author}

Suresh C. Tyagi, Department of Physiology and Biophysics, Health Sciences Center, A-1115, University of Louisville, Louisville, KY 40292, USA. Fax: 1-(502) 852-6239. E-mail: s0tyag01@louisville.edu

\section{Introduction}

Chronic volume overload-induced heart failure predisposes to left ventricular remodeling (Cox et al. 2004). The matrix metalloproteinases (MMPs) are a family of zinc-dependent endopeptidases which contribute to tissue remodeling in a number of disease states (Nagase and Woessner 1999). In normal myocardium the MMPs are present in the latent form (Tyagi et al. 1993). Various reports suggest an increase in oxidative stress after chronic VO (Belch et al. 1989, Prasad et al. 1996). It is well known that the oxidative stress activates latent resident myocardial MMPs (Tyagi et al.1993, Cox et al. 2002, Hunt et al. 2002).

In a failing myocardium the MMPs activation results in a decrease in elastin/interstitial collagen ratio which leads to the accumulation of oxidized extracellular matrix (ECM) (Mebazza et al. 1995, Tyagi et al. 1993) and alters endothelial to myocyte distance (Michel et al. 1986). Very recently, we have shown that an increase in oxidative and proteolytic stress induces endocardial endothelial-myocyte (EM) uncoupling after chronic volume overload in mice (Moshal et al. 2005). Furthermore, the administration of cardiac tissue inhibitor of MMP-4 (CIMP/TIMP-4) restores EM uncoupling.

In general, the activation of MMP-2 and MMP-9 is a prominent phenomenon during the early and the late phase of chronic heart failure (CHF), respectively (Tyagi et al. 1996). The recent study from our lab has determined the specific involvement of MMP-9 activation in endocardial endothelial cell apoptosis leading to the impairment of cardiac functions in chronic VO-induced heart failure (Ovechkin et al. 2005), but the 
role of MMP-9 activation on the LV endocardial endothelial-myocyte functions after chronic VO remains obscure.

This study tested the hypothesis that the increased MMP-9 activity in the myocardial LV directly contributes to the EM disconnection in a mice model of chronic VOinduced heart failure. We report that MMP-9 activation in the late phase of CHF induces EM uncoupling. Furthermore, the targeted deletion of $M M P 9$ gene restores the EM functions.

\section{Methods}

Mice

Eight- to ten-week-old male mice lacking MMP-9 (MMP-9KO, FVB.Cg-Mmp9 ${ }^{\mathrm{tm} 1 \mathrm{Tvu}}$ ) and their genetically identical wild type (WT) mice (FVB/NJ) weighing 27-30 g, procured from Jackson Laboratories (Bar Harbor, ME) were used. Animal experimentations were performed according to the protocols approved by the Institutional Animal Care and Use Committee of the University of Louisville. All animal care and use programs were carried out according to National Institutes of Health Guide for the Care and Use of Laboratory Animals (NIH Pub. No. 8623, Revised 1985) and the regulations of the Animal Welfare Act. The phenotype analysis for MMP-9KO mice was performed using in-gel-gelatin zymography on blood plasma samples.

\section{Experimental design and infrarenal arteriovenous fistula} (AVF)

AVF was created as described elsewhere (Ovechkin et al. 2005, Moshal et al. 2005). Briefly, a fistula was created between the aorta and the caudal vena cava $\sim 0.5 \mathrm{~cm}$ below the left kidney using 30 -gauge needle in the mice. Sham-operated mice were used as control and underwent the same procedure with exception of the aortocaval shunt. Since heart becomes decompensated at eighth week (Moshal et al. 2005) the mice were anesthetized after 8-10 weeks and the heart was excised and processed for experimentations.

\section{In-gel gelatin zymography}

Zymography using $1 \%$ gelatin gel was performed on blood plasma and LV tissue homogenates as described elsewhere (Tyagi et al. 1993) with slight modification. Briefly, blood plasma was collected and the LV myocardial samples were homogenized in $5 \mathrm{ml}$ of an icecold extraction buffer (1:3 wt/vol) containing cacodylic acid (10 mmol/l), $\mathrm{ZnCl}(20 \mathrm{mmol} / \mathrm{l}), \mathrm{NaN}_{3}(1.5 \mathrm{mmol} / \mathrm{l})$, and $0.01 \%$ Triton $\mathrm{X}-100(\mathrm{pH} 5.0)$. The homogenate was then centrifuged $\left(4^{\circ} \mathrm{C}, 10 \mathrm{~min}, 800 \mathrm{x} \mathrm{g}\right)$. The supernatant and the plasma were assayed for protein concentration using Bradford assay and $100 \mu \mathrm{g}$ of the protein was electrophoresed in $7.5 \%$ SDS-PAGE containing $1.5 \%$ gelatin as MMP substrate under non-reducing conditions. After SDS-PAGE, the gels were washed in $2.5 \%$ Triton X100 for $30 \mathrm{~min}$, rinsed in water, and incubated overnight in developing buffer at $37{ }^{\circ} \mathrm{C}$ with gentle shaking $(50 \mathrm{mmol} / \mathrm{l}$ Tris- $\mathrm{HCl}, 5 \mathrm{mmol} / 1 \mathrm{CaCl}_{2}$, and $0.02 \% \mathrm{NaN}_{3}, \mathrm{pH} 7.5$ ).

\section{Endocardial endothelial-myocyte coupling}

The "deli"-shaped LV rings were prepared by removing the right ventricular wall and were mounted between two wires in a tissue myobath as described elsewhere (Moshal et al. 2005). The ring was stretched and brought to resting tension at which $10 \mathrm{nM}$ endothelin-1 (ET-1) was added. Contractile responses to drugs affecting cardiac function [acetylcholine (ACh), bradykinin (BK), and nitroprusside (Npr)] were measured in endothelin (ET)-1-contracted rings. The percent relaxation was based on $100 \%$ ET-1 contraction. To avoid the ischemia, $95 \%$ $\mathrm{O}_{2}-5 \% \mathrm{CO}_{2}$ was continuously bubbled through the myobath. The experiments were completed within $40 \mathrm{~min}$ to minimize the injury due to ischemia (Tyagi et al. 1999).

\section{Statistical analysis}

Values are given as means $\pm \mathrm{SD}(6$ mice per group). Differences between groups were evaluated by one-way ANOVA. $P<0.05$ was considered statistical significant.

\section{Results}

\section{Functional analysis of mouse phenotype}

Blood plasma was collected from the indicated group of mice and subjected to gelatin zymography. After 8 weeks of AVF, a robust increase in MMP-9 activation was observed as compared to the sham controls. There was a significant decrease in MMP-9 activation in the mice with targeted deletion of $M M P 9$ gene after chronic VO (Fig. 1). Note- MMP-2 activity is present in MMP-9KO mice.

\section{MMP-9 activity levels in LV homogenates}

The effect of AVF on the activity levels of MMP9 in myocardial LV was determined. After 8 weeks of AVF, myocardial LV homogenates was prepared as 


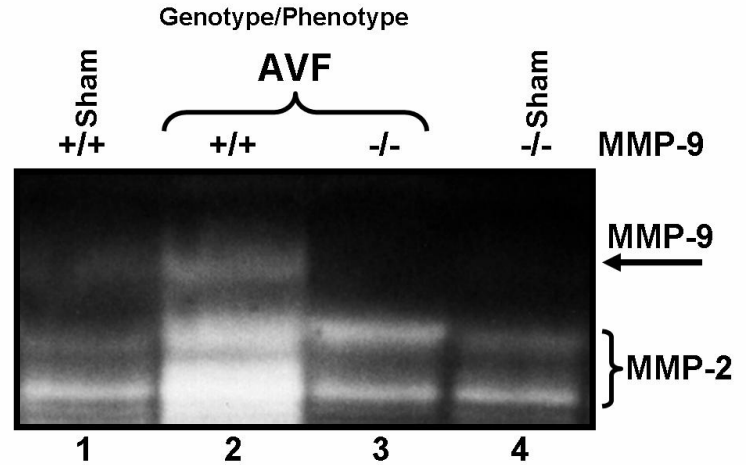

Fig. 1. MMP-9KO mice phenotype analysis. Blood plasma was collected from the indicated groups and analyzed for phenotype using gelatin zymography. For AVF and sham operated group, the plasma was collected at $8^{\text {th }}-10^{\text {th }}$ week. A representative zymogram is shown ( $n=6$ mice in each group).

mentioned in Materials and Methods section from the indicated groups and were subjected to the in-gel-gelatin zymography. We observed an increase in the MMP-9 activity in AVF mice as compared to the sham controls. Interestingly, MMP-9 KO mice with AVF showed a significant decrease in MMP-9 activity in myocardial LV homogenates (Fig. 2). An increase in MMP-2 activity after chronic VO was observed, but MMP-2 activity was decreased in MMP-9KO after AVF. This may suggest a synergism in MMPs family.

Endocardial endothelial-myocyte response to drugs affecting cardiac function

To determine whether increased MMP-9 activity was associated with the impairment of EM functions after chronic $\mathrm{VO}$, the ex vivo myocardial $\mathrm{LV}$ rings were prepared as described in Materials and Methods and the responses to $\mathrm{ACh}, \mathrm{BK}$, and $\mathrm{Npr}$ were measured in myocardial LV rings from the indicated groups of mice. We observed a significant decrease of the relaxation to Ach (Fig. 3b) and Npr (Fig. 3d) responses in the AVF mice compared to the sham controls. BK induces a significant increase in contraction in AVF mice compared to the sham controls (Fig. 3c). Interestingly, in MMP-9 KO mice with AVF, we observed that the AVF-induced impairment in EM functions was restored.

\section{Discussion}

Previously we have shown that the chronic overload of the left ventricle increases oxidative stress and activates matrix metalloproteinases (MMPs) which compromises the cardiac functions, in part by endocardial endothelial-myocyte (EM) disconnection (Moshal et al.

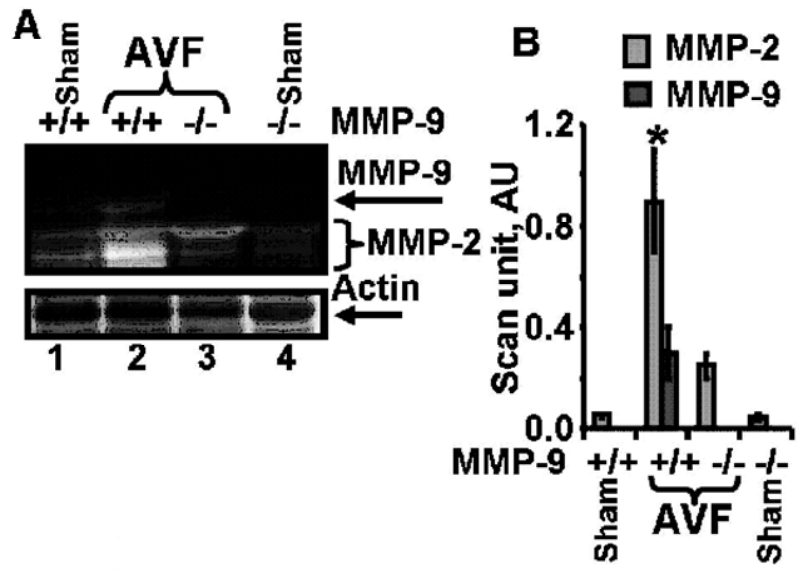

Fig. 2. MMP gelatinolytic activity in LV homogenates. A. LV homogenate was prepared as mentioned under Materials and Methods section from the indicated group of mice and analyzed for MMP activity using in-gel-gelatin zymography. A representative zymogram is shown. Corresponding actin bands are shown. B. Scanned values for MMP-9 and -2 were normalized with that of actin and represented as histogram. Data are presented as mean \pm S.E.M. from 6 animals in each group. $*$ Statistical significance $(p \leq 0.05)$

2005). Furthermore, the administration of CIMP/TIMP-4 ameliorates AVF-induced endocardial endothelial cell apoptosis and EM uncoupling, in part by decreasing proteolytic and oxidative stress.

It is suggested that the targeted deletion of $M M P 9$ gene attenuates LV remodeling (Duchrame et al. 2000, Romanic et al. 2002). However, the mechanism underlying the LV remodeling by MMP-9 activation is not well understood. A recent study from our lab has provided the evidence for the specific involvement of MMP-9 in cardiac dysfunction in mice model of CHF and showed that the impaired myocardial functions is due to the endocardial endothelial cell apoptosis. EM coupling is an important decisive factor for the maintenance of myocardial functions, but the role of MMP-9 activation on the LV endocardial endothelial-myocyte functions after chronic $\mathrm{VO}$ is not known.

In the present study we specifically report a lossof-functions for EM coupling in mice with AVF. Furthermore, the targeted deletion of $M M P 9$ gene resulted in the gain-of-functions for EM coupling after chronic VO on myocardial LV.

We noticed an increase in MMP-2 activity after chronic VO. However, we observed a decrease in MMP-2 activity in MMP-9KO after AVF. This may be attributed to the synergism in MMPs family. Coordination between angiogenesis and cardiac hypertrophy is the hallmark of compensatory response to heart failure, however, a 

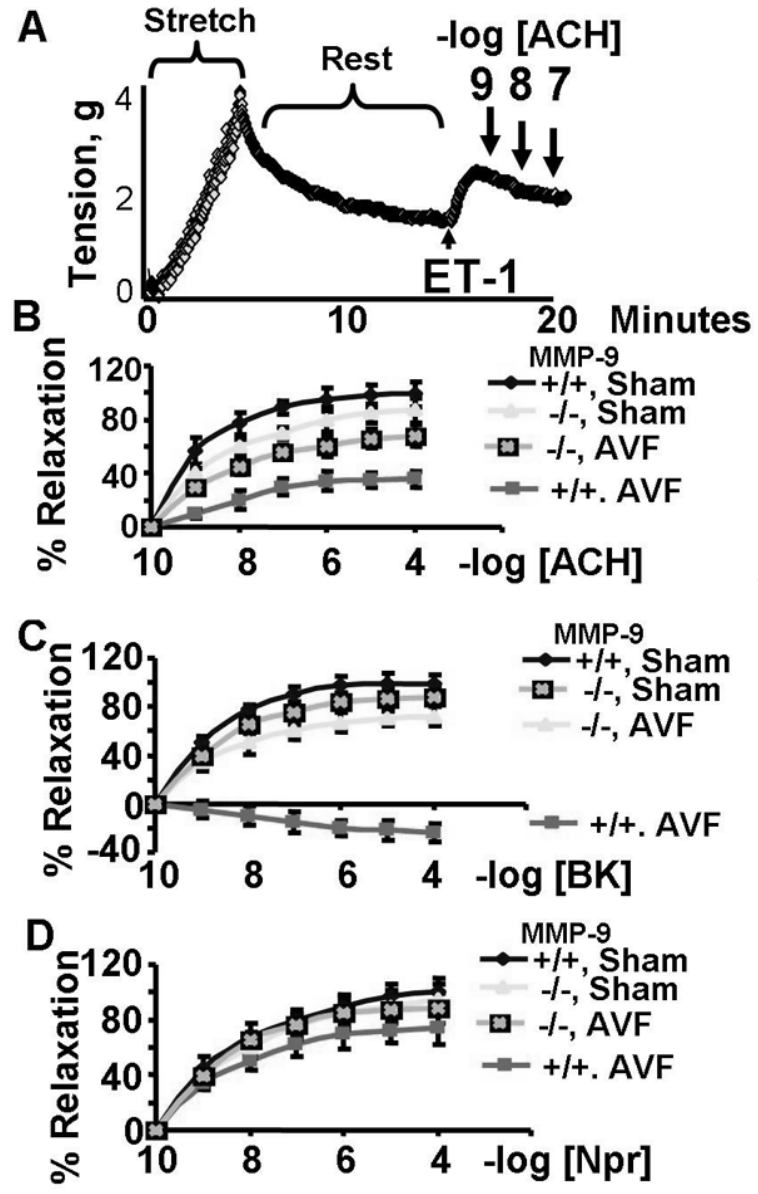

Fig. 3. Endocardial endothelial-myocyte functions. A. LV rings were prepared and mounted in a tissue myobath and analyzed for endothelial-myocyte functions as mentioned in Materials and Methods. LV rings from the control mice were stretched, brought to resting tension, and contracted with $10 \mathrm{nM}$ endothelin (ET)-1. Different doses of acetylcholine (ACh) were added to the ring in a tissue myobath. The relaxation to ACh was estimated as the percent ET-1 contraction. A representative contractile response to ET-1 and relaxation to $10^{-9}, 10^{-8}$, and $10^{-7} \mathrm{M} \mathrm{ACh}$ is shown. $\mathbf{B}$. ACh dose-response curves representing the best fit of the data in indicated group of mice. C. endocardial endothelial response to bradykinin (BK) doses. Curves represent the best fit of the data from indicated group of mice. D. response of endocardial endothelium to the different doses of nitroprusside (Npr). Curves represent best fit of the data. Data are means $\pm S D(n=6$ animals in each group).

disruption in coordination between cardiac hypertrophy and angiogenesis contributes to the transition to heart failure (Shiojima et al. 2005). It is a paradox that activation of MMP is required for matrix degradation during angiogenesis, but the peptides generated by MMP activation are angiostatic (O'Reilly et al. 1997). The decrease in MMP-2 and increase in MMP-9 in hypertension is consistent with the notion that MMP-2 is constitutive and MMP-9 is inducible and causes discoordinated matrix degradation leading to decompensated hypertrophy and heart failure by generation of angiostatic factors.

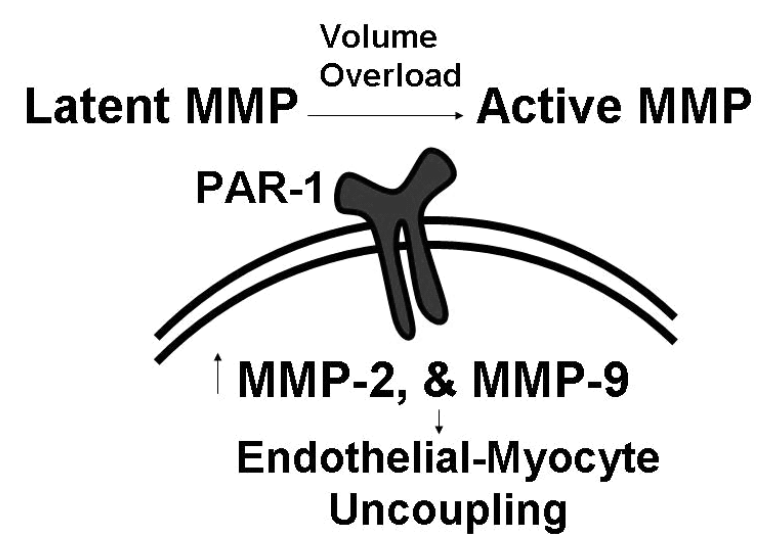

Fig. 4. Schematic representation of hypothesis. Chronic volume overload activates MMP-9, protease activated receptor-1 leading to myocardial contractile dysfunction, in part by endocardial endothelial-myocyte disconnection.

We studied the EM functions using various drugs affecting cardiac function. ACh stimulates nitric oxide (NO) release in the isolated heart preparation (Gattuso et al. 1999). Our lab has demonstrated that increased levels of MMP activity are associated with decreased levels of endocardial endothelial $\mathrm{NO}$ in response to the increased levels of ROS during heart failure (Hunt et al. 2002). MMPs were activated and the levels of cardiac inhibitor of metalloproteinase (CIMP) were decreased in congestive heart failure (CHF) (Cox et al. 2002, Hunt et al. 2002). We have shown that the administration of TIMP-4/CIMP ameliorated the oxidative-proteolytic stress and endothelial-myocyte uncoupling in chronic heart failure in mice and CIMP treatment induced the NO production in endocardial endothelial cells (Moshal et al. 2005). In accordance with these findings, we speculate that there will be an increase in CIMP/TIMP-4 levels in MMP-9 KO mice which may induce the NO accumulation. Therefore we may suggest that EM uncoupling was ameliorated in AVF mice with the targeted deletion of MMP9 gene. BK induces relaxation via EDHF pathways (Miura et al. 1999). In the present study we have observed the contraction in response to BK, which may suggest the alteration in arachidonic acid metabolites in CHF. Oxidative and proteolytic stresses play a pivotal role in the modulation of the BK effect. Targeted deletion of MMP-9 ameliorates BK-induced contraction after AVF. The response to endothelium-independent nitroprusside is also attenuated in AVF mice and suggests that the underlying cardiac muscle and non-endothelial cells were also affected by oxidative stress in AVF mice. Restoration of EM functions in MMP-9 KO mice after AVF may be attributed to the decreased ROS generation.

The results from the present study support our 
hypothesis (Fig. 4) that chronic VO-induced heart failure is associated with the activation of MMP-9, which leads to cardiac dysfunction in part by, impairing EM functions.

\section{Conflict of Interest}

There is no conflict of interest.

\section{Acknowledgements}

This research was supported, in part by, American Heart Association Post-Doctoral Training Grant (award \# 0625579B) (to Karni S. Moshal), NIH Grant HL-74185 S (to Walter E. Rodriguez), and NIH Grants HL-71010, HL-74185 (to Suresh C. Tyagi).

\section{References}

BELCH JJ, CHOPRA M, HUTCHINSON S, LORIMER R, STURROCK RD, FORBES CD, SMIT WE: Free radical pathology in chronic arterial disease. Free Radic Biol Med 6: 375-378, 1989.

COX MJ, SOOD HS, HUNT MJ, CHANDLER D, HENEGAR JR, ARU GM, TYAGI SC: Apoptosis in the left ventricle of chronic volume overload causes endocardial endothelial dysfunction in rats. Am J Physiol 282: H1197-H1205, 2002.

COX MJ, HAWKINS UA, HOIT BD, TYAGI SC: Attenuation of oxidative stress and remodeling by cardiac inhibitor of metalloproteinase protein transfer. Circulation 109: 2123-2128, 2004.

DUCHARME A, FRANTZ S, AIKAWA M, RABKIN E, LINDSEY M, ROHDE L, SCHOEN F, KELLY R, WERB Z, LIBBY P, LEE R: Targeted deletion of matrix metalloproteinase-9 attenuates left ventricular enlargement and collagen accumulation after experimental myocardial infarction. $J$ Clin Invest 106: 55-62, 2000.

GATTUSO A, MAZZA R, PELLEGRINO D, TOTA B: Endocardial endothelium mediates luminal acetylcholine-nitric oxide signaling in isolated frog heart. Am J Physiol 276: H633-H641, 1999.

HUNT MJ, ARU GM, HAYDEN MR, MOORE CK, HOIT BD, TYAGI SC. Induction of oxidative stress and disintegrin metalloproteinase in human heart end-stage failure. Am J Physiol 283: L239-L245, 2002.

MEBAZAA A, WETZEL R, CHERIAN M, ABRAHAM M: Comparison between endothelial and great vessel endothelial cells: morphology, growth, and prostaglandin release. Am J Physiol 268: H250-H259, 1995.

MICHEL JB, SALZMANN JL, NLOM MO, BRUNEVAL P, BARRES D, CAMILLERI JP: Morphometric analysis of collagen network and plasma perfused capillary bed in the myocardium of rats during evolution of cardiac hypertrophy. Basic Res Cardiol 81: 142-154, 1986.

MIURA H, LIU Y, AND GUTTERMAN DD: Human coronary arteriolar dilation to bradykinin depends on membrane hyperpolarization: contribution of nitric oxide and $\mathrm{Ca}^{2+}$-activated $\mathrm{K}^{+}$channels. Circulation 99: 3132-3138, 1999.

MOSHAL KS, TYAGI N, HENDERSON B, OVECHKIN AV, TYAGI SC: Protease activated receptor and endothelial-myocyte uncoupling in chronic heart failure. Am J Physiol 288: H2770-H2777, 2005.

NAGASE H, WOESSNER JF Jr. Matrix metalloproteinases. J Biol Chem 274: 21491-21494, 1999.

OVECHKIN AV, TYAGI N, RODRIGUEZ WE, HAYDEN MR, MOSHAL KS, TYAGI SC: Role of matrix metalloproteinase-9 in endothelial apoptosis in chronic heart failure in mice. J Appl Physiol 99: 2398-2405, 2005.

O’REILLY MS, BOEHM T, SHING Y, FUKAI N, VASIOS G, LANE WS, FLYNN E, BIRKHEAD JR, OLSEN BR, FOLKMAN J: Endostatin: an endogenous inhibitor of angiogenesis and tumor growth. Cell 88: 277-285, 1997.

PRASAD K, GUPTA JB, KALRA J, LEE P, MANTHA SV, BHARADWAJ B: Oxidative stress as a mechanism of cardiac failure in chronic volume overload in canine model. J Mol Cell Cardiol 28: 375-385, 1996.

ROMANIC A, HARRISON S, BAO W, BURNS-KURTIS C, PICKERING S, GU J, MAO J, SATHE G, OHLSTEIN E, YUE T: Myocardial protection from ischemia/reperfusion injury by targeted deletion of matrix metalloproteinase-9. Cardiovasc Res 54: 549-558, 2002.

SHIOJIMA I, SATO K, IZUMIYA Y, SCHIEKOFER S, ITO M, LIAO R, COLUCCI WS, WALSH K: Disruption of coordinated cardiac hypertrophy and angiogenesis contributes to the transition to heart failure. $J$ Clin Invest 115: 2059-2064, 2005. 
TYAGI SC, MATSUBARA L, WEBER KT: Direct extraction and estimation of collagenase(s) activity by zymography in micro quantities of rat myocardium and uterus. Clin Biochem 26: 191-198, 1993.

TYAGI SC, RATAJSKA A, WEBER KT: Myocardial matrix metalloproteinases: localization and activation. Mol Cell Biochem 126: 49-59, 1993.

TYAGI SC, HAAS SJ, KUMAR SG, REDDY HK, VOELKER DJ, HAYDEN MR, DEMMY TL, SCHMALTZ RA, CURTIS JJ. Post-transcriptional regulation of extracellular matrix metalloproteinase in human heart end-stage failure secondary to ischemic cardiomyopathy. J Mol Cell Cardiol 28: 1415-1428, 1996.

TYAGI SC, SMILEY LM, MUJUMDAR VS: Homocyst(e)ine impairs endocardial endothelial function. Can J Physiol Pharmacol 77: 950-957, 1999. 